\title{
Laurel Tangyuan and Fuwan Chocolate Incident - How to do better people-oriented external communication
}

\author{
WenWei Liao ${ }^{1 *}$, WenWen Yang ${ }^{1}$, WeiTsen Lin ${ }^{1}$, JoChi Hsu ${ }^{1}$, PeiShiou Kao ${ }^{1}$, ChangChi Chen ${ }^{1}$, PengFei \\ Lin $^{1}$, YuShun Pon ${ }^{2}$ \\ ${ }^{1}$ Executive Education Executive MBA, Aalto University \\ Aalto University Foundation sr PO BOX 11000 FI-00076 AALTO, FINLAND (Helsinki, Finland) \\ ${ }^{2}$ Cooperative Institute for Research in Environmental Sciences at University of Colorado Boulder \\ 325 Broadway (Boulder, U.S.A) \\ ${ }^{*}$ Corresponding author's email: Abard.AALTO [AT] gmail.com
}

\begin{abstract}
The "Fuwan Chocolate", which originated in Pingtung, Taiwan, is a world-famous chocolate brand. In 2020, "Fuwan" won the gold medal during the "World Chocolate Competition", which known as the "Oscar Award" in the chocolate industry. After winning the grand prize, "Fuwan Chocolate" took advantage of the momentum and launched joint products with well-known brands, such as Laurel Corp (Tangyuan). Unexpectedly, the father of Fuwan's CEO sexually harassed a female intern five years ago, and the CEO also scolded the victim for the chaotic private life after his father being accused. This old matter that has been 5 years was brought up to the stage again this year. Although Fuwan apologized on their Facebook fan page afterwards, it was not accepted by netizens. After three weeks of uproar, its co-branded manufacturer Laurel announced the suspension of production of chocolate flavor tangyuan in collaboration with Fuwan. Many well-known Taiwanese manufacturers also followed the step in the meanwhile. The established credibility and image are now seriously damaged. This study is mainly to discuss the external communication methods and processing results of "Fuwan" and "Laurel" by comparing the pros and cons of their processing methods. We hope this research will be able to provide a better people-oriented communication method that may combined with local condition as a reference when same incident once happened in the future.
\end{abstract}

Keywords- External Communication, People-Oriented, Laurel Tang Yuan (Tangyuan), Fuwan Chocolate

\section{INTRODUCTION}

After winning the gold medal in the World Chocolate Competition in 2020, Taiwan's local chocolate company"Fuwan Chocolate" has launched joint products with many well-known Taiwanese brands. Unexpectedly, netizens revealed that the chairman had sexually harassed a female intern five years ago, and the CEO even issued an article on the internet to abuse the victim. As result, there was a strong boycott action has been raised, and another company, Laurel Corp, was also involved in the turmoil and then recalled its products immediately.

In the evening of January 10, 2015, the former chairman of Fuwan saw the female intern washing cups alone in the cafeteria and asked her whether she have had gained weight. He then pinched the female intern's waist and buttocks from rear, ignoring the intern's rejecting response, and even embraced her waist from behind. Afterwards, the former chairman of Fuwan was convicted, and also sentenced including compensation obligation in 2016. Moreover, the female intern was maliciously being dismissed sooner after the incident. Regarding this action, the chairman of Fuwan was being accused again and then found guilty with sentenced requiring compensation by the court on June 30, 2016. The CEO of Fuwan wrote a post on Facebook after the lawsuit, criticizing the female intern in December 2015. The female intern later learned that then filed another lawsuit to accuse the CEO. Eventually, the court sentenced that the CEO was found guilty and must compensate the victim.

A female netizen posted an article in the "Dcard" forum on November 15 this year, mentioned that the Fuwan has recently launched a joint collaboration with many brands, begin with "A past sexual harassment news that seem to be forgotten, here to help everyone remind it", the sexual harassment case of Fuwan which happened five years ago was once again being brought to the top. The post caused an outrage, and a wave of boycotts was then also being set off among the public. 
After three weeks of the uproar, the co-branded manufacturer Laurel Corp announced that it would stop producing chocolate "glutinous rice balls" (hereafter called "Tangyuan") that cooperated with Fuwan, and many well-known Taiwanese manufacturers also followed up the action, greatly damaging the reputation and image that Fuwan had hardly established. This study is mainly to discuss the external communication methods and processing results of "Fuwan" and "Laurel" by comparing the advantages and disadvantages of their processing methods. We hope this research will be able to provide a better people-oriented communication method that combined with local condition as a reference when same incident once happened in the future.

\section{LITERATURE REVIEW}

\subsection{The pride of Taiwan- Fuwan Chocolate}

There are two grand chocolate competitions in the chocolate industry, the "Academy Of Chocolate (AOC)" and "International Chocolate Awards (ICA)", which are known as the "Golden Globe" and "Oscar Awards", are the most desired rewards for chocolate craft master and lovers. The Academy Of Chocolate (AOC) was founded in 2005, led by Michel Roux, who is the contemporary British Michelin Three-Star rewarded legendary chef, united with the Royal Academy of Culinary Arts Chairman-Sara Jayne Stanes, Pierre Hermé and headquarters of Selfridge \& Co.'s UK. The AOC was the most trending dream team of evaluation that being the earliest one to promote the fine chocolates. [1]

At the 2018 AOC campaign, there were about 1,200 products from more than 45 countries participated. The "Fuwan Manor Chocolate" from Pingtung, Taiwan, was participated for the first time, and they eventually won 2 gold medals in the competition with their $62 \%$ Taiwan's No. 5 cocoa nibs chocolate and $62 \%$ Taiwan's Tieguanyin tea flavor chocolate. They also got great results of wining 4 silver medals and 4 bronze medals on other items. The Fuwan showed to the world for Taiwan's local cocoa agriculture and chocolate craftsmanship. [2]

In November 2019, at the ICA (International Chocolate Awards) "World Chocolate Competition" global finals that held in Guatemala, the chairman of the conference announced to the guests, saying "Attention everyone, here comes the Taiwan chocolate in full fury!". [3] This sentence also officially announced to the world that Taiwan has already occupied a place in the chocolate market. The one who led Taiwan to share the honor is a local brand of Taiwanese chocolate from Pingtung-Fuwan Chocolate. In that year, Fuwan Chocolate ranked first by wining 5 gold, 19 silver, and 4 bronze rewards during the ICA (International Chocolate Awards) [4] "World Chocolate Competition. In the meanwhile, in the chocolate category, Fuwan also won the "World's Best Dark Chocolate" award that has been always dominated by Peruvian companies over the years, with their "Taiwan No. 1 Pingtung Dark Chocolate 62\%". It may be said that Fuwan Chocolate was the best in Taiwan.

\section{The Top Brand of Taiwanese Tangyuan-Laurel Tangyuan}

"Laurel" is a well-known brand of frozen food provider in Taiwan. It has dominated the frozen food industry in Taiwan for over 50 years. [5] There are more than 100 popular products in the channel. In its early history, Laurel started the business by selling ice cubes and renting out freezer. Later, they aimed the target to the frozen food industry since most of the family had a refrigerator. In 1975, the laurel Tangyuan were first appeared on the market. Until 1978, Laurel Tangyuan has become the most popular brand of Tangyuan.

In addition to the retail channels of Laurel, the shipments of traditional market and the allocation of convenience stores are the reasons why Laurel Tangyuan has a huge market share. In addition, Laurel has also joined e-commerce, and people with specific needs would buy frozen foods through e-commerce. The COVID-19 epidemic has triggered panic buying of groceries. During the pandemic period of the covid-19, all kinds of Laurel products are sold out, even "Tangyuan" were in a shortage. [6] Therefore, during such circumstances, the strategy of Laurel is to meet consumer needs as much as possible. As people have more chance eating at home, the frequency of consuming Laurel products has also increased.

How to turn a fifty-year-old brand into a trendy brand is a new idea that Laurel wants to try out. In recent years, Laurel has successively launched joint series with many well-known brands. For example, the Matcha flavor Tangyuan were collaboratively launched with the famous Japan Kyoto matcha shop- Tsujiri Tea Shop, has reached the record of selling 600,000 boxes in half a year. [7] Later, Laurel and Fuwan Chocolate were accidentally involved in the wellknown sexual harassment case in 2020. How they resolve this matter is also the focus of this research.

\subsection{Sexual Harassment Incident of Fuwan affect Laurel Tangyuan}

Laurel launched the first chocolate flavor Tangyuan to the market on December 4, 2020. The filling was $70 \%$ of mild dark chocolate and topped with top grade French citrus paste. It was originally expected to create another sales boom after the hot selling matcha flavor Tangyuan. However, unexpectedly, it was revealed by netizens that the chocolate 
ingredients were imported by Fuwan, while Fuwan's former chairman was provoked by suspected sexual harassment of female employee case in 2015. Even in recent years, there are many international award-winning and domestic crossover collaboration products, however, the brand image was strongly damaged by the sexual harassment incident, and it also dragged down the collaborative brands.

Laurel issued a statement on their official Facebook fan page in the evening of December 7, 2020, clarifying that the product will be discontinued immediately, and all of its related selling income will also be donated to the charity. On December 8th, the collaborative brands, such as SAKImoto Bakery, Guai Guai, Mister Donut, Family Mart, Carrefour, and Sunmai, announced that all the Fuwan co-branded products will be recalled.

Regarding the situation of the co-branded products being recalled or discontinued, Fuwan Chocolate once again posted an announcement as response to their official Facebook fan page in the evening of December 8 , stating that they have had also issued an official explanation about the incident to those co-branded collaborative brands when they posted their apology statement on the fan page on November 27, expressed they respect for all the decisions of the partner after assessing the revenue, and was willing to bear the sales loss of the collaborating brand, and also stated that "We are willing to make every effort to let consumers regain their trust and love for Fuwan Chocolate."

\section{DISCUSSION}

\subsection{Analyses from web database}

From the "OpView" social media listening database, we tracked the changes in the topic volume of Fuwan Chocolate in the online community and found that the negative volume of Fuwan Chocolate reached a high point on December 7 , 2020. In addition, tracking the topics related to Fuwan Chocolate and sexual harassment in the past month, on a weekly basis, it can be observed that the number of topics increased sharply in the week of December 7 th, and there are 1,180 articles related to Fuwan Chocolate and sexual harassment incident. Prior to this, the highest weekly topics were only about 24, which is equivalent to an increase of nearly 50 times. From the "OpView social media listening database ", it can also be found that there are many discussions about the raw materials of the Laurel Chocolate Tangyuan and Fuwan when they are on the market.

After the Fuwan sexual harassment incident outbreaks, the negative volume of the Laurel chocolate tangyuan became higher and higher. In order to calm the outrage of netizens, Laurel issued an explanation on their Facebook fan page on December 5, claimed that the Fuwan just assisted in importing raw materials from overseas, not directly supplying raw materials, but netizens do not accept the saying, and more than 300 netizens clicked "anger" at the post. Since this announcement could not calmed the public, Laurel decided to cut off with Fuwan immediately on December 7 th, announcing that this product would be discontinued. The big movement reversed the situation and made netizens applauded. Guai Guai, Mister Donut, Family Mart and other collaborated brands are also following the action.

\subsection{External Communication Method of Fuwan}

Fuwan Chocolate was boycotted by the netizens on the Girl board of "Dcard" forum on December 15, 2020. The Angry netizens supposed that everyone seemed to have forgotten the past sexual harassment incident, and then sorted out related reports and verdicts, expecting everyone help to remind the process of the incident and launched the campaign of "Refuse to Buy Sexual-Harassed Chocolate". Due to the rapid spread of this activity, Fuwan issued their first statement of apologize to the Facebook fan page on November 27, but netizens believed that they were insincere, so they continued to publish articles in the "Fuwan Chocolate" fan professional statement posts, and criticized a large number of response were being deleted; after well-known brands such as SAKImoto, Guai Guai, Mister Donut, Laurel and other co-branded partners rapidly said that related products would be recalled, Fuwan issued an apology for the second time, which still could not stop the outrage from the netizens.

However, some netizens held different aspect of view and left some messages in support of "Fuwan, GO!", "Your chocolate is unbelievably delicious, I will continue to support you, and I hope you may well-behaved and continue to make chocolates for everyone". Some netizens even mentioned conspiracy theories that it was the opponent's jealous, they opened up the five-year old scandal and damage the reputation. An internet celebrity has issued a post, saying that "it is reasonable for netizens to refuse to buy Fuwan Chocolate products, but it does not mean that those companies who use Fuwan's raw materials agree with sexual harassment". It may be seen that although the reputation was affected, there are still some people who continue to support the good products. At present, Fuwan Chocolate adopts a do-nothing policy by stop saying anything temporarily, hoping that the time will reduce the outrage. 


\subsection{External Processing Method of Laurel}

Laurel's statement pointed out that "We will be on the same side with consumers. Therefore, the production of "Laurel Chocolate Tangyuan" will be stopped from now on. All the selling income related to the " Laurel Chocolate Tangyuan" will be donated to public welfare. Choosing partners will also be more cautiously in the future". Although Laurel Corp issued an urgent public relations statement at first, stating that the chocolate was not produced by Fuwan Chocolate but was imported through the company, a large number of netizens still expressed boycott of the company's related products. Finally, Laurel issued a new statement to stop the production of "Laurel Chocolate Tangyuan". The related selling income will be donated to charity. This statement not only won the support and appreciation of many consumers, but also become a model for many brands in turning crisis into opportunity. It also allowed consumers' decision to affect the decision making from company's administration once again. The choice of consumers has determined the outcome of this incident eventually.

\section{CONCLUSION AND SUGGESTION}

The gold medal winner of World Chocolate Competition, Pingtung's "Fuwan Chocolate", who took advantage of Taiwan's top reputation and launched joint products with major famous brands. Unexpectedly, an online article made it fell on the way of rising. Analyzing its external communication methods with the online community, Fuwan communicated with a careless attitude from the beginning. Since Taiwanese are extremely valued sincerity, a backlash was generated. But Fuwan did not care, they downplayed the situation, and this time an even greater counter strike were made for sure. It also caused other companies who collaborated with Fuwan to cut off immediately, which not only brought the loss of their own goodwill, but also suffered great economic losses.

During the incident, Laurel has made good use of their image of "cherishing food". First, the selling income of 33,229 boxes of "Chocolate Tangyuan" for a total of NTD \$2,957,381, were being donated to "The Garden of Hope Foundation". In addition, after the outbreak of the scandal, 71,793 boxes of "Laurel Chocolate Tangyuan" that were voluntarily recalled and returned to the warehouse by the channel were being prepared for registered non-profit organizations in the domestic Taiwan to request for free, and the delivery with be arranged in early January of 2021 successively. In such perfect way, people in need may get warm food, it reversed their image and turned from a evil company to an ethical one. This flawless way of communicating with the media has become the best example of corporate external communication. Facing the 70,000 boxes of "brand bomb" it should be, Laurel successfully took the advantage of "food cherish" to turn the crisis into an opportunity.

According to the crisis management method of external communication, we know that a good open letter must include a few things: 1 . Make the readers feel that we are the same party 2 . Lead positive action 3 . Give the brand a role to let the public know the role of the enterprise in certain crisis. 4. Participate in the dialogue and invite everyone to solve issues together. 5. Make the readers moved with emotion. In this incident, Laurel did everything that mentioned in the above while Fuwan did nothing. This is also the main reason that result in Fuwan's failure.

In this operation, Fuwan should let everyone know that the company has learned their lesson and will resolutely oppose sexual harassment in the future. In addition, positive action must be taken, such as active compensation, public welfare, and donations to women's groups. Second, we must face our own role and become a guardian ambassador for women. In addition, scholars and experts should also be invited, in order to fully compensate the society. Finally, touching with sincerity and emotion, reflect on own mistakes, and apologize again for previous improper manner, then it may be able to reduce the loss of the incident.

\section{REFERENCES}

[1] Stephie Chiu (2018) Fuwan is super. Fuwan won 2 gold medals in the 2018 AOC campaign, Magazine Title, Shopping Design. Retrived from https://www.shoppingdesign.com.tw/post/view/2918

[2] Zhang, Yuan-Zhang (2018) Taiwan Chocolate won 2 gold medals in the 2018 AOC campaign, Magazine Title, Epoch Times Taiwan. Retrived from https://www.epochtimes.com/gb/18/5/19/n10408748.htm

[3] Kuo, Si-Yu (2019) Taiwa Chocolate Won Again, Fuwan won the International Chocolate Awards again. Magazine Title, Shopping Design. Retrived from https://www.shoppingdesign.com.tw/post/view/4826

[4] Hsu, Shin-Yi (2020) An interview with Fuwan CEO - By using a Tree to bar model to make a famious Taiwan chocolate around the world. Magazine Title, Shopping Design. Retrived from

https://www.shoppingdesign.com.tw/post/view/5120 
[5] Economic Daily News (2020) Laurel does not only "Tangyuan" in winter! How does the 50-year-old frozen food dominator make consumers pay all year round? MagazineTitle, Buisness Next. Retrived from https://www.bnext.com.tw/article/57474/laurel-50

[6] Ho, Show-Ling (2020) Not only sells "Tangyuan" in the winter, but the laurels hope that you will buy their frozen foods for all seasons Magazine Title, Manager today. Retrived from

https://www.managertoday.com.tw/articles/view/59668

[7] Tsai, Lu-Hang (2018) The secret of precise succession. Magazine Title, ET Today. Retrived from https://finance.ettoday.net/news/1314083 